\title{
GC-MS analysis of allergens in plant oils meant to cosmetics
}

Jacques KALOUSTIAN ${ }^{1}$

Céline MIKAIL ${ }^{1}$

Tarek EL-MOSELHY²

Lydia ABOU ${ }^{1}$

Henri PORTUGAL ${ }^{1}$

${ }^{1}$ Laboratoire de chimie analytique

(Faculté de pharmacie) et

UMR mixte Aix-Marseille 2 - INSERM 476 -

INRA 1260

(Faculté de Médecine),

Université de la Méditerranée,

27 Boulevard Jean Moulin,

13385 Marseille Cedex 5, France

$<$ lacques.Kaloustian@pharmacie.univ-mrs.fr>

${ }^{2}$ Department of Pharmaceutical Chemistry,

Faculty of Pharmacy, Tanta University, Tanta

31527, Egypt

Article received on 20/06/2006

accepted on 20/12/2006

\begin{abstract}
Cutaneous allergy occurs mainly as a result of the use of domestic products and cosmetics. Some fragrances, present in these products, may contain compounds that are responsible for allergy (allergens). The European Council offered a Directive limiting the level of 26 allergens found in cosmetics. GC-MS technique was used to determine the retention times of 25 allergens, determine detection and quantification limits and make calibration with standard solution of each allergen in concentrations ranging from 10 to $200 \mathrm{mgL}^{-1}$ (21 allergens) and 50 to $200 \mathrm{mgL}^{-1}$ (4 allergens). Quantification was performed by the use of 2 internal standards (tetradecane and hexadecane). Seven oils issued from plants were studied by GC-MS. For all of them, the concentration of potential allergens was lower than their minimum detectable level. The alcoholic solution of extracts issued from different samples of oil did not demonstrate the presence of any quantifiable allergen, even when was concentrated 25 times. GC-MS could be a useful technique in the identification and, if necessary, quantification of allergen in ingredients meant to cosmetics.
\end{abstract}

Key words: GC-MS, allergens, ingredients meant to cosmetics, plant oils, European Council Directive

\section{Introduction}

Allergy falls under three main categories: 1) respiratory such as pollens (trees and herbs) and hair of animals (cats); 2) alimentary such as fruits (strawberry), shellfish, fish, eggs, pharmaceuticals (antibiotics) and 3) cutaneous such as bites of insects (bees and wasps) and industrial products such as domestic products and cosmetics. Cutaneous allergy is accompanied by eczema, hives or oedema of Quincke. The treatment includes the use of antihistamines, corticosteroids and desensitisation as well. The most common reaction to fragrance materials is the allergic contact dermatitis [1].

The increased use of perfumes, essential oils and plant extracts in cosmetics and deodorants, has involved an increased incidence of allergy [2-10]. In addition, domestic products, containing fragrances, have increased eczema of the hands [11-13].

Essential oils are volatile oily substances immiscible with water and usually have a density value lower than one. They have a complex chemical composition (mono- and sesqui- terpenes, oxidised substances and aromatics) [14]. In most cases, the essential oils can be obtained by aqueous distillation, squeezing out from Citrus epicarps or dry distillation. Some essential oils can be modified. Redistilled essential oils are deprived of one or several constituents.

Oil and plant extracts may contain ingredients showing, a pharmacological activity inconsistent with a cosmetic use, or potential risk of toxicity to the consumer. The European Council presented a Directive relating to cosmetic products. Twenty six fragrances have been considered as cutaneous contact allergens. The European Union has decided that they should be kept below 100 ppm in products that are designed to be applied to the body and then rinsed off, such as soaps, and must be below $10 \mathrm{ppm}$ in products that are designed to remain on the body throughout the day, such as perfumes. This Directive can be of great value for the consumers capable of reacting to these components and for helping the dermatologists in the diagnosis of cutaneous allergenic reactions [15].

The allergens may be present in natural essential oils or obtained by synthetic ways. Allergenic activity could be due to oxidised derivatives, such as peroxides, as in case of limonene and linalool. On the contrary, phenols present in natural essential oils (lavender), have antioxidant properties and can protect from allergenic reactions [16-24].

Several publications have described the use of Gas Chromatography-Mass Spectrometry (GC-MS) technique in the qualitative and quantitative analysis of many compounds present in essential oils and perfumes [25-32].

The detection and quantification limits for each allergen were determined by GC-MS technique. The regression equations of each allergen standard used in calibration were presented. It also was important to search and determine the allergens in several plant oils. 


\section{Experimental}

\section{Allergens}

The allergens and their CAS No are listed in table 1. All standards were purer than $95 \%$. To this list methyl-2-octynoate was added. In contrary, the last two components of the list (oak moss and tree moss extracts) were not injected into $\mathrm{GC}$, because they are non volatile.

\section{Sample preparation}

Pure essential oils were not tested, because GC studies were described in several references [26-30]. Seven oils issued from plants and produced by S.A. Huiles Bertin (60330 - Lagny-Le-Sec, France) were studied: virgin oil of Sisymbrium, virgin oil of Hazel Nuts, virgin oil of Sweet Almonds, virgin oil of Souchet, virgin oil of Cashew Nuts, virgin oil of Borage, castor oil. 2.5 to $5 \mathrm{~g}$ of vegetable oils was stirred with $10.0 \mathrm{~mL}$ alcohol $(96 \%)$ or hexane during 15 minutes. Only the alcoholic (or hexanic) solution was injected into GC. Sometimes, this solution was concentrated 10 or 25 times, by heating at $75{ }^{\circ} \mathrm{C}$, for $15 \mathrm{~min}$, under nitrogen sweeping.

\section{Gas chromatography conditions}

Tests were done on GC-MS instrument, Varian 3400 - Saturn 4D ion trap. A capillary column $(30 \mathrm{~m} \times 0.32 \mathrm{~mm}$ ID $\times 1 \mu \mathrm{m}$ DB5 film with $5 \%$ phenylmethyl silicon). Initial temperature was held for $1 \mathrm{~min}$ at $60^{\circ} \mathrm{C}$ then heated at $3{ }^{\circ} \mathrm{C} \mathrm{min}-1$ until $200{ }^{\circ} \mathrm{C}$. Then the temperature was held at $200^{\circ} \mathrm{C}$ for $30 \mathrm{~min}$. Temperatures of the injector and detector were 250

Table 1. List of Allergens from the European Directive 2003/15/CE.

\begin{tabular}{|lc|}
\hline Skin-sensitising ingredients (trivial name and & CAS No \\
synonyms) & \\
\hline Amylcinnamal or 2-benzylideneheptanal & $122-40-7$ \\
Benzyl alcohol or $\alpha$-hydroxytoluene & $100-51-6$ \\
Cinnamyl alcohol or 3-phenyl-2-propen-1-ol & $104-54-1$ \\
Citral or neral or geranial or 3,7-dimethyl-2,6-octadien-1-al & $5392-40-5$ \\
Eugenol or 4-allyl-1-hydroxy-2-methoxybenzene & $97-53-0$ \\
Hydroxycitronellal or 3,7-dimethyl-7-hydroxyoctanal & $107-75-5$ \\
Isoeugenol or 4-hydroxy-3-methoxy-1-propenylbenzene & $97-54-1$ \\
Amylcinnamyl alcohol or 2-pentyl-3-phenylprop-2-ene-1-ol & $101-85-9$ \\
Benzyl salicylate or benzyl-2-hydroxybenzoate & $118-58-1$ \\
Cinnamal or 3-phenyl-2-propenal & $104-55-2$ \\
Coumarin or 2-oxo-1,2-benzopyran & $91-64-5$ \\
Geraniol or 2-trans-3,7-dimethyl-2,6-octadien-1-ol & $106-24-1$ \\
\hline Lyral or 4-(4-hydroxy-4methyl-pentyl) cyclohex- & $31906-04-4$ \\
3enecarbaldehyde & \\
Anisyl alcohol or 4-methoxybenzylic alcohol & $105-13-5$ \\
Benzyl cinnamate or 3-phenyl-2-propenoic acid & $103-41-3$ \\
phenylmethyl ester & \\
Farnesol or 3,7,11-trimethyl-2,6,10-dodecatrien-1-ol & $4602-84-0$ \\
Lilial or 2-(4-tert-butylbenzyl)propionaldehyde & $80-54-6$ \\
Linalool or 3,7-dimethylocta-1,6-dien-3-ol & $78-70-6$ \\
Benzyl benzoate or benzyl benzenecarboxylate & $120-51-4$ \\
Citronellol or 3,7-dimethyl-6-octen-1-ol & $106-22-9$ \\
Hexylcinnamaldehyde or 2-hexyl-3-phenyl-2-propenal & $101-86-0$ \\
d-Limonene or (R)-p-mentha-1,8-diene & $5989-27-5$ \\
Methyl-2-octynoate or methyl heptin carbonate & $111-12-6$ \\
3-Methyl- $\alpha$-ionone or 3-methyl-4-(2,6,6-trimethyl-2- & $127-51-5$ \\
cyclohexene-1-yl)-3-butene-2-one or $\gamma$-isomethylionone & $90028-68-5$ \\
Evernia prunastri extract or oak moss extract & \\
Evernia furfuracea extract or tree moss extract & \\
\hline
\end{tabular}

and $285^{\circ} \mathrm{C}$, respectively. The carrier gas used was helium and supplied at $138 \mathrm{kPa}$ head pressure. A $1 \mu \mathrm{L}$ sample was injected in splitless mode.

\section{Detection limit}

The concentration of allergen at which the peak was equal or higher than 3 times the background noise was retained (Detection Limit or DL).

\section{Qualitative analysis}

Identification was made according to retention times and mass spectra. Three MS libraries were used: NIST, Wiley and TR.

\section{Quantification limit}

The concentration of allergen at which the peak was equal or higher than 10 times the background noise was retained (Quantification Limit or QL).

\section{Quantitative analysis}

It was based on internal standardisation, using tetradecane and hexadecane as internal standards. Five standard solutions, included in the range of 10 to $200 \mathrm{mg} \mathrm{L}^{-1}$ of each allergen, were used in calibration. Intervals of calibration were 50 to $200 \mathrm{mg} \mathrm{L}^{-1}$ for benzyl alcohol, anisyl alcohol, cinnamyl alcohol and coumarin.

Table 2. Retention times (RT) determination of the allergen standards.

\begin{tabular}{|c|c|c|c|}
\hline Allergen studied & $\begin{array}{c}\text { Mean RT } \\
\quad(\mathrm{sec})\end{array}$ & SD & RSD (\%) \\
\hline Limonene & 890 & 0.75 & 0.084 \\
\hline Benzyl alcohol & 921 & 0.71 & 0.077 \\
\hline Linalool & 1098 & 0.75 & 0.068 \\
\hline Methyl-2-octynoate & 1395 & 0.98 & 0.070 \\
\hline Citronellol & 1475 & 0.75 & 0.049 \\
\hline Citral ( $1^{\text {st }}$ isomer $)$ & 1517 & 0.75 & 0.049 \\
\hline Geraniol & 1550 & 0.63 & 0.041 \\
\hline Citral ( $2^{\text {nd }}$ isomer $)$ & 1602 & 0.63 & 0.039 \\
\hline Cinnamal & 1640 & 4.96 & 0.30 \\
\hline Hydroxycitronellal & 1662 & 1.33 & 0.080 \\
\hline Anisyl alcohol & 1680 & 7.07 & 0.42 \\
\hline Methyl-2-nonynoate * & 1686 & 0.89 & 0.053 \\
\hline Cinnamyl alcohol & 1743 & 6.36 & 0.36 \\
\hline Eugenol & 1857 & 0.75 & 0.040 \\
\hline Coumarin & 2116 & 0.71 & 0.034 \\
\hline Isoeugenol & 2130 & 1.10 & 0.051 \\
\hline 3-Methyl- $\alpha$-ionone & 2183 & 1.03 & 0.047 \\
\hline Lilial & 2328 & 1.05 & 0.045 \\
\hline Farnesol ( $1^{\text {st }}$ isomer) & 2570 & 1.87 & 0.073 \\
\hline Amylcinnamal & 2624 & 1.10 & 0.042 \\
\hline Farnesol ( $2^{\text {nd }}$ and $3^{\text {rd }}$ isomers $)$ & 2634 & 1.67 & 0.063 \\
\hline Amylcinnamyl alcohol ( $1^{\text {st }}$ isomer) & 2658 & 0.75 & 0.028 \\
\hline Lyral ( $1^{\text {st }}$ isomer) & 2663 & 1.79 & 0.067 \\
\hline Lyral ( $2^{\text {nd }}$ isomer $)$ & 2682 & 1.67 & 0.062 \\
\hline Farnesol ( $4^{\text {th }}$ isomer) & 2690 & 1.95 & 0.072 \\
\hline Amylcinnamyl alcohol ( $2^{\text {nd }}$ isomer) & 2719 & 0.52 & 0.019 \\
\hline Hexylcinnamaldehyde & 2861 & 1.10 & 0.038 \\
\hline Benzyl benzoate & 2930 & 1.05 & 0.036 \\
\hline Benzyl salicylate & 3233 & 0.52 & 0.016 \\
\hline Benzyl cinnamate & 4335 & 2.37 & 0.055 \\
\hline
\end{tabular}

* was not cited in the EC Directive. Standard solutions were prepared in absolute ethanol in a concentration about $1 \mathrm{~g} \mathrm{~L}^{-1}$. SD = standard deviation; RSD = relative standard deviation. 


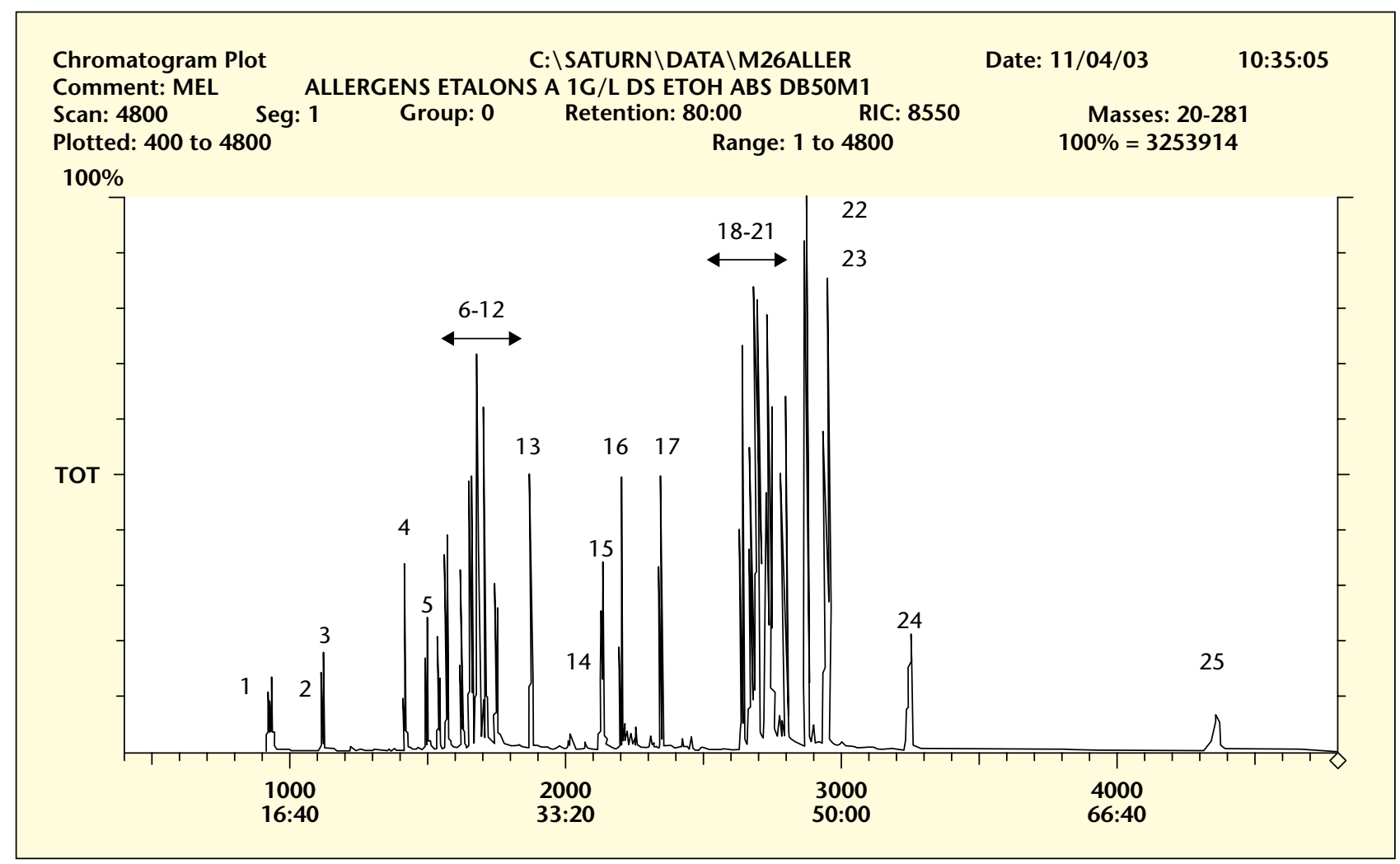

Figure 1. The chromatogram of the 25 allergen standard mixture.

\section{Quantification repeatability}

Ten tests were done showing a relative standard deviation lower than $2.5 \%[28]$.

\section{Results and discussion}

\section{Retention times (TR) determination}

Ten tests for each standard (about $1 \mathrm{~g} \mathrm{~L}^{-1}$ in absolute alcohol), present in known mixtures, were performed. The mean value of the retention times (RT), standard deviation (SD) and relative standard deviation (RSD), for each allergen standard, are shown in table 2. All RSDs were lower than $0.084 \%$ except for cinnamal 0.30 , anisyl alcohol 0.42 and cinnamyl alcohol 0.36 , respectively.

Three allergens (citral, amylcinnamyl alcohol and lyral) consist of two isomers and one allergen (farnesol) consists of four isomers. The \% of each isomer was determined by internal normalisation and shown as follows: Citral, $1^{\text {st }}$ peak (neral) at $1517 \mathrm{sec}(46.3 \%)$ and $2^{\text {nd }}$ peak (geranial) at $1602 \mathrm{sec}(53.7 \%)$; amylcinnamyl alcohol, $1^{\text {st }}$ peak at 2658 $\mathrm{sec}(49.0 \%)$ and $2^{\text {nd }}$ peak at $2719 \mathrm{sec}(51.0 \%)$; lyral $1^{\text {st }}$ peak at $2663 \mathrm{sec}$ $(23.9 \%)$ and $2^{\text {nd }}$ peak at $2682 \mathrm{sec}(76.1 \%)$ and farnesol $1^{\text {st }}$ peak at 2570 $\sec (8.6 \%), 2^{\text {nd }}$ and $3^{\text {rd }}$ peaks (together) at $2634 \mathrm{sec}(43.8 \%)$ and $4^{\text {th }}$ peak at $2690 \mathrm{sec}(47.6 \%)$.

Allergens frequently co-elute with other fragrance plant ingredients, so, mass spectrometry (MS) will be necessary for identification.

\section{Determination of detection and quantification limits of each allergen}

First, a mixture of 25 allergen standards (mother solution), each about 1 to $2 \mathrm{~g} \mathrm{~L}^{-1}$ was studied. The chromatogram is shown in figure 1 .
Then, 3-known mixtures were prepared in alcohol (about $1 \mathrm{~g} \mathrm{~L}^{-1}$ ) and injected into GC. The composition of the 3-known mixtures is given as follows: 20 allergens (limonene, linalool, methyl-2-octynoate, citronellol, citral (2 isomers), geraniol, cinnamal, hydroxy-citronellal, methyl-2nonynoate, cinnamyl alcohol, eugenol, coumarin, 3-methyl- $\alpha$-ionone, lilial, amylcinnamal, amylcinnamylalcohol (2 isomers), hexylcinnamal, benzyl benzoate, benzyl salicylate and benzyl cinnamate); 5 allergens (benzyl alcohol, anisyl alcohol, isoeugenol, lyral ( 2 isomers) and benzyl benzoate) and 2 allergens (farnesol (4 isomers) and benzyl benzoate). Then several dilutions (1/10 to $1 / 1000)$ were made on these mother solutions and injected into GC. The retained DLs and QLs are shown in table 3. When two or four isomers were present, only the major peak was considered.

\section{Fundamentals of allergen identification}

The following steps were performed:

1) In the chromatogram of unknown plant oil, the peaks with RT close to those of allergen standards was searched.

2) If the peak height was 3 times lower than the background noise, the peak was considered absent.

3) If the height of the peak was 3 times higher than the background noise, the peak was considered present.

4) Identification was done when the theoretical RT given by TR library corresponded to the observed RT of the unknown peak, and we compared mass spectra of the unknown peak with those of allergen standards, and after with those standards present in libraries.

5) If a doubt arose about the peak, we re-injected the unknown plant oil enriched with the expected standard. Identification will be confirmed if only one peak appeared without a shoulder.

6) If the height of the peak was 10 times higher than the background noise, quantification would be possible. 
Table 3. Retained detection limit (DL) and quantification limit $(Q L)$ for each allergen in mixture.

\begin{tabular}{|c|c|c|}
\hline Allergen studied & $\begin{array}{c}\text { Retained } \\
\text { detection } \\
\text { limit }\left(\mathbf{m g ~ L}^{-1}\right)\end{array}$ & $\begin{array}{c}\text { Retained } \\
\text { quantification limit } \\
\left(\mathbf{m g ~ L}^{-1}\right)\end{array}$ \\
\hline Limonene & 2.1 & 11 \\
\hline Benzyl alcohol & 40 & 72 \\
\hline Linalool & 2.4 & 17 \\
\hline Methyl-2-octynoate & 2.2 & 16 \\
\hline Citronellol & 2.2 & 18 \\
\hline Citral ( $1^{\text {st }}$ or $2^{\text {nd }}$ isomer $)$ & 11.5 & 35 \\
\hline Geraniol & 10.1 & 28 \\
\hline Cinnamal & 30 & 66 \\
\hline Hydroxycitronellal & 4.5 & 25 \\
\hline Anisyl alcohol & 50 & $\sim 100$ \\
\hline Methyl-2-nonynoate & 4.8 & 21 \\
\hline Cinnamyl alcohol & 43 & 86 \\
\hline Eugenol & 10.9 & 27 \\
\hline Coumarin & 33 & $\sim 100$ \\
\hline Isoeugenol & 12.6 & 30 \\
\hline 3-Methyl- $\alpha$-ionone & 2.5 & 12 \\
\hline Lilial & 2.1 & 12 \\
\hline Amylcinnamal & 12.8 & 26 \\
\hline Amylcinnamyl alcohol ( $2^{\text {nd }}$ isomer) & 2.6 & 25 \\
\hline Lyral ( $2^{\text {nd }}$ isomer $)$ & 3.9 & 26 \\
\hline $\begin{array}{l}\text { Farnesol } \\
\left(2^{\text {nd }} \text { and } 3^{\text {rd }} \text { isomers }\right)\end{array}$ & 11.8 & 32 \\
\hline Hexylcinnamaldehyde & 2.2 & 11 \\
\hline Benzyl benzoate & 11.4 & 24 \\
\hline Benzyl salicylate & 11.6 & 38 \\
\hline Benzyl cinnamate & 37 & 75 \\
\hline
\end{tabular}

\section{Quantification of the allergens present in the samples}

The calibration of each allergen was done with the use of two internal standards: tetradecane and hexadecane (table 4). The choice of internal standard depends on the presence of interfering peaks. The retention times (sec) of several saturated hydrocarbons were tested and found to be 520,790, 1390, 1967, 2230 and 2490 for nonane, decane, dodecane, tetradecane, pentadecane and hexadecane, respectively. A linear correlation was observed, $\mathrm{Y}=284.39 \mathrm{X}-2037.8, \mathrm{Y}=$ retention time, $\mathrm{X}=$ number of carbons, $\mathrm{R}=0.9998$ and $\mathrm{p}<0.001$. In this paper the choice of tetradecane and hexadecane was based on the best results obtained by analysing different samples. They appeared in retention times that were fairly different from other peaks present in all the samples.

\section{Results of studied samples}

Our chromatographic procedure seemed to be slightly longer than that described before [30], but our conditions showed good resolution for about 200 terpenoid compounds determined in general essential oil studies.

From the 25 studied standard allergens, 19 showed a retained DL lower than $13 \mathrm{mg} \mathrm{L}^{-1}$ and 5 were between 30 and $50 \mathrm{mg} \mathrm{L}^{-1}$. These variations are well explained by the form of the peaks. A narrow and high peak gave a value lower than $13 \mathrm{mg} \mathrm{L}^{-1}$, in contrary, a broad and low height peak gave a higher value of $\mathrm{DL}$.

GC-MS is considered as a good technique for the determination of volatile substances. Results were obtained with good repeatability.
Table 4. The calibration data for compounds listed as skin-sensitising ingredients.

\begin{tabular}{|c|c|c|}
\hline Allergen Studied & $\begin{array}{l}\text { Regression } \\
\text { Equation* }\end{array}$ & $\left(\mathbf{R}^{2}\right)^{* *}$ \\
\hline \multirow[t]{2}{*}{ Limonene } & $y=9.5033 x+0.0114$ & 0.9958 \\
\hline & $y=8.3883 x+0.0134$ & 0.9975 \\
\hline \multirow[t]{2}{*}{ Benzyl alcohol } & $y=2.9113 x-0.0243$ & 0.9938 \\
\hline & $y=2.6244 x-0.0201$ & 0.9922 \\
\hline \multirow[t]{2}{*}{ Linalool } & $y=8.6162 x+0.0143$ & 0.9991 \\
\hline & $y=7.4624 x+0.0157$ & 0.9979 \\
\hline \multirow[t]{2}{*}{ Methyl-2-octynoate } & $y=7.5282 x+0.0103$ & 0.9986 \\
\hline & $y=6.5170 x+0.0058$ & 0.9980 \\
\hline \multirow[t]{2}{*}{ Citronellol } & $y=8.4145 x+0.0259$ & 0.9968 \\
\hline & $y=7.2836 x+0.0273$ & 0.9952 \\
\hline \multirow[t]{2}{*}{ Citral ( $1^{\text {st }}$ isomer) } & $y=5.6307 x+0.0052$ & 0.9982 \\
\hline & $y=4.8689 x+0.0025$ & 0.9990 \\
\hline \multirow[t]{2}{*}{ Geraniol } & $y=8.6412 x+0.0002$ & 0.9963 \\
\hline & $y=7.4762 x+0.0036$ & 0.9929 \\
\hline \multirow[t]{2}{*}{ Citral ( $2^{\text {nd }}$ isomer $)$} & $y=5.2198 x+0.0015$ & 0.9985 \\
\hline & $y=4.5067 x+0.0009$ & 0.9975 \\
\hline \multirow[t]{2}{*}{ Cinnamal } & $y=7.0368 x-0.0617$ & 0.9946 \\
\hline & $y=6.2324 x-0.0617$ & 0.9935 \\
\hline \multirow[t]{2}{*}{ Hydroxycitronellal } & $y=8.9758 x+0.0618$ & 0.9976 \\
\hline & $y=7.7788 x+0.0566$ & 0.9953 \\
\hline \multirow[t]{2}{*}{ Anisyl alcohol } & $y=2.7664 x-0.0139$ & 0.9955 \\
\hline & $y=3.9782 x+0.0063$ & 0.9990 \\
\hline \multirow[t]{2}{*}{ Methyl-2-nonynoate } & $y=8.0496 x+0.0521$ & 0.9925 \\
\hline & $y=7.1888 x+0.0259$ & 0.9951 \\
\hline \multirow[t]{2}{*}{ Cinnamyl alcohol } & $y=3.9441 x+0.0061$ & 0.9902 \\
\hline & $y=3.7575 x-0.0027$ & 0.9970 \\
\hline \multirow[t]{2}{*}{ Eugenol } & $y=7.9359 x+0.0262$ & 0.9977 \\
\hline & $y=6.8756 x-0.0186$ & 0.9939 \\
\hline \multirow[t]{2}{*}{ Coumarin } & $y=6.0366 x-0.0021$ & 0.9990 \\
\hline & $y=5.2234 x-0.0186$ & 1.0000 \\
\hline \multirow[t]{2}{*}{ Isoeugenol } & $y=4.3897 x+0.0139$ & 0.9955 \\
\hline & $y=3.9782 x+0.0063$ & 0.9990 \\
\hline \multirow[t]{2}{*}{ 3-Methyl- $\alpha$-ionone } & $y=11.267 x+0.0408$ & 0.9976 \\
\hline & $y=9.7537 x+0.0411$ & 0.9981 \\
\hline Lilial & $y=11.252 x+0.0100$ & 0.9997 \\
\hline & $y=9.7475 x+0.0193$ & 0.9992 \\
\hline Farnesol ( $1^{\text {st }}$ isomer) & $y=3.4526 x-0.0008$ & 0.9924 \\
\hline & $y=3.4522 x-0.0011$ & 0.9969 \\
\hline Amylcinnamal & $y=12.960 x+0.0574$ & 0.9974 \\
\hline & $y=11.224 x+0.0571$ & 0.9961 \\
\hline Farnesol & $y=3.3175 x-0.0032$ & 0.9994 \\
\hline ( $2^{\text {nd }}$ and $3^{\text {rd }}$ isomers) & $y=3.4368 x-0.0046$ & 0.9987 \\
\hline Amylcinnamyl alcohol & $y=6.3332 x+0.0574$ & 0.9949 \\
\hline ( $1^{\text {st }}$ isomer) & $y=5.4199 x+0.0512$ & 0.9912 \\
\hline Lyral ( $1^{\text {st }}$ isomer $)$ & $y=10.494 x+0.0038$ & 0.9994 \\
\hline & $y=9.2450 x-0.0008$ & 0.9999 \\
\hline Lyral $\left(2^{\text {nd }} \text { isomer }\right)^{* * *}$ & $y=7.3230 x-0.0162$ & 0.9982 \\
\hline & $y=6.3827 x-0.0158$ & 0.9980 \\
\hline Farnesol ( $4^{\text {th }}$ isomer) & $y=3.2928 x-0.0079$ & 0.9930 \\
\hline & $y=3.4702 x-0.0078$ & 0.9903 \\
\hline Amylcinnamyl alcohol & $y=5.0437 x+0.0333$ & 0.9992 \\
\hline ( $2^{\text {nd }}$ isomer) & $y=4.3181 x+0.0301$ & 0.9982 \\
\hline Hexylcinnamaldehyde & $y=13.896 x+0.0421$ & 0.9917 \\
\hline & $y=12.026 x+0.0422$ & 0.9922 \\
\hline Benzyl benzoate & $y=11.739 x-0.0039$ & 0.9908 \\
\hline & $y=10.158 x+0.0011$ & 0.9930 \\
\hline Benzyl salicylate & $y=7.0125 x-0.0578$ & 0.9966 \\
\hline & $y=6.0679 x-0.0474$ & 0.9960 \\
\hline Benzyl cinnamate & $y=11.739 x-0.0039$ & 0.9908 \\
\hline & $y=10.158 x+0.0011$ & 0.9930 \\
\hline
\end{tabular}

$\left(^{*}\right) 1^{\text {st }}$ data for tetradecane and $2^{\text {nd }}$ for hexadecane when used as internal standards; $\mathrm{y}=$ ratio of (allergen peak area/internal standard peak area); $\mathrm{x}=$ concentration of allergen $\left.\left(\mathrm{g} \mathrm{L}^{-1}\right) ;{ }^{(* *}\right) \mathrm{R}=$ correlation coefficient; $\left({ }^{* * *}\right)$ only the $2^{\text {nd }}$ isomer of lyral (the largest peak) must be quantified. 
To avoid a possible volatilisation or degradation of allergens, ethanolic solutions were prepared and injected quickly. Solutions were not kept more than one day at $4{ }^{\circ} \mathrm{C}$.

Ethanol is a good solvent for extraction. It dissolves several fractions of vegetable oils, but sometimes hexane will be prefered. For a good extraction, the solvent should be added in excess (2-5 times) more than the volume of the sample. So, to increase the sensitivity, it was necessary to concentrate this alcoholic (or hexanic) extract, 10 to 25 times. But in this case, losses were observed due to volatilisation. In each case, standard solutions were prepared and concentrated in the same conditions as that the studied samples. Allergen loss percentage was then determined. Limonene, benzyl alcohol, linalool, citronellol, citral, cinnamaldehyde, anisyl alcohol and cinnamyl alcohol lose 55\% (75\%), 15.5\% (23\%), 10\% (23\%), 13\% (19\%), 20\% (31\%), 20\% (20.5\%), 26\% (33\%) and 10\% (20.5\%) when were concentrate 10 times (25 times), respectively. All the others lost less than $10 \%$. Concentration of 10 and 25 times can improve the determination of $\mathrm{DL}$

\section{Result expression}

Results expression would be done according to the following model: $5.0434 \mathrm{~g}$ of Borage oil were stirred with $10.0 \mathrm{~mL}$ of alcohol (96\%) during $15 \mathrm{~min}$. After centrifugation, the alcoholic volume was $9.0 \mathrm{~mL}$. Then, 10 times concentrated solution was injected into GC. Limonene was considered present ( 3 times the background noise) and corresponded to the Minimum Detectable Level (MDL), in this concentrated solution $(\mathrm{VC}=0.90 \mathrm{~mL})$.

$\mathrm{DL} * \mathrm{VC}=2.1 * 0.90 * 10^{-3}=1.89 \mu \mathrm{g}$ of limonene in the sample. If we take into account the initial mass of plant oil $(5.0434 \mathrm{~g})$ and the loss of $55 \%$ of limonene in 10 times concentration, corrected MDL will be: $(1.89 * 100) / 5.0434 *(100-55)=0.83 \mu \mathrm{g}$ of limonene per $1 \mathrm{~g}$ of Borage oil.

\section{All tested oils had potential allergen level lower than DL.}

The fragrance mix (FM) is the main screening chemicals used to test for fragrance allergy. FM is composed of $1 \%$ of the following 8 chemicals: cinnamal, cinnamyl alcohol, eugenol, isoeugenol, hydroxycitronellal, geraniol, oak moss absolute and amylcinnamaldehyde. Dermatologists have used FM mixture as a standard to test cutaneous allergy. The composition of this mixture should be extended to include other allergens [33-37]. The GC-MS technique, described here, could be applied in allergen determination, in plant oils meant to cosmetics. Evaluation of allergens in cosmetics will be less easier.

Acknowledgements. F. Turon (S.A. Huiles Bertin) for supplying several samples of plant oils.

\section{REFERENCES}

1. LARSEN WG. Perfume dermatitis. / Am Acad Dermatol 1985; 12: 1-9.

2. DE GROOT AC, BRUYNZEEL DP, BOS JD, et al. The allergens in cosmetics. Arch Dermatol 1988; 124: 1525-9.

3. FROSCH PJ, PILZ B, ANDERSEN KE, et al. Patch testing with fragrances: results of a multicenter study of the European Environmental and Contact Dermatitis Research Group with 48 frequently used constituents of perfumes. Contact Dermatitis 1995; 33: 333-42.

4. SCHEINMAN PL. Allergic contact dermatitis to fragrance: a review. Am J Contact Dermat 1996; 7: 65-76.

5. LARSEN W, NAKAYAMA H, LINDBERG $M$, et al. Fragrance contact dermatitis: a worldwide multicenter investigation (Part 1). Am / Contact Dermat 1996; 7: 77-83.

6. LARSEN W, NAKAYAMA $H$, FISCHER $H$, et al. Fragrance contact dermatitis: a worldwide multicenter investigation (Part 2). Contact Dermatitis 2001; 44: 344-6.
7. KATZ AS, SHERERTZ EF. Facial dermatitis: patch test results and final diagnoses. Am / Contact Dermat 1999; 10: 153-6.

8. RASTOGI SC, JOHANSEN JD, MENNE T, et al. Contents of fragrance allergens in children's cosmetics and cosmetic-toys. Contact Dermatitis 1999; 41: 84-8.

9. LUNDER T, KANSKY A. Increase in contact allergy to fragrances: patch-test results 1989-1998. Contact Dermatitis 2000; 43: 107-9.

10. SCHEINMAN PL. Prevalence of fragrance allergy. Dermatology 2002; 205: 98-102.

11. RASTOGI SC, HEYDORN S, JOHANSEN JD, BASKETTER DA. Fragrance chemicals in domestic and occupational products. Contact Dermatitis 2001; 45: 221-5.

12. GIMENEZ-ARNAU A, GIMENEZ-ARNAU E， SERRA-BALDRICH E， LEPOITTEVIN JP, CAMARASA JG. Contact Dermatitis 2002; 47: 345-52.

13. HEYDORN S, MENNE T, JOHANSEN JD. Contact Dermatitis 2003; 48: 59-66.

14. BRUNETON J. Pharmacognosy. Paris: Tec and Doc Ed, 1999; (3rd Ed.).

15. Directive 2003/15/CE of European Parliament and Council relating to cosmetic products of 27 February 2003, Official Journal of the European Union of 11.03.2003, L 66/26-35.

16. KARLBERG AT, MAGNUSSON K, NILSSON U. Air oxidation of d-limonene (the citrus solvent) creates potent allergens. Contact Dermatitis 1992; 26: 332-40.

17. KARLBERG AT, SHAO LP, NILSSON U, GAFVERT E, NILSSON JL. Hydroperoxides in oxidized d-limonene identified as potent contact allergens. Arch Dermatol Res 1994; 286: 97-103.

18. KARLBERG AT, DOOMS-GOOSSENS A. Contact allergy to oxidized d-limonene among dermatitis patients. Contact Dermatitis 1997; 36: 201-6.

19. NILSSON U, MAGNUSSON K, KARLBERG O, KARLBERG AT. Are contact allergens stable in patch test preparations? Investigation of the degradation of d-limonene hydroperoxides in petrolatum. Contact Dermatitis 1999; 40: 127-32.

20. KARLBERG AT, BASKETTER D, GOOSSENS A, LEPOITTEVIN JP. Regulatory classification of substances oxidized to skin sensitizers on exposure to air. Contact Dermatitis 1999; 40: 183-8.

21. MATURA M, GOOSSENSA, BORDALO O, et al. Oxidized citrus oil (R-limonene): a frequent skin sensitizer in Europe. Am Acad Dermatol 2002; 47: 709-14.

22. SKOLD M, BORJE A, MATURA M, KARLBERG AT. Studies on the autoxidation and sensitizing capacity of the fragrance chemical linalool, identifying a linalool hydroperoxide. Contact Dermatitis 2002; 46: 267-72.

23. MATURA M, GOOSSENS A, BORDALO O, et al. Patch testing with oxidized R-(+)-limonene and its hydroperoxide fraction. Contact Dermatitis 2003; 49 : 15-21.

24. BASKETTER DA, WRIGHT ZM, COLSON NR, PATLEWICZ GY, SITH PEASE CK. Investigation of the skin sensitising activity of linalool. Contact Dermatitis 2002; 47: 161-4.

25. RASTOGI SC. Analyses of Fragrances in Cosmetics by GC-MS. / High Resol Chromatogr 1995; 18: 653-8.

26. RASTOGI SC, JOHANSEN JD, FROSCH P, et al. Deodorants on the European market: quantitative chemical analysis of 21 fragrances. Contact Dermatitis 1998; 38: 29-35.

27. RASTOGI SC, LEPOITTEVIN JP, JOHANSEN JD, et al. Fragrances and other materials in deodorants: search for potentially sensitising molecules using combined GC-MS and structure activity relationship (SAR) analysis. Contact Dermatitis 1998; 39: 293-303.

28. KALOUSTIAN I, PAULI AM, PASTOR J. Evolution of camphor and other components in the essential oil of two labiate species during the biological cycle. Analusis 2000; 28: 308-15. 
29. ELLENDT K, HEMPEL G, KÖBLER H. Analysis of sensitiving fragrances by GC-MS. SÖFW-Journal 2001; 127: 29-34.

30. CHAINTREAU A, JOULAIN D, MARIN C, SCHMIDT CO, VEY M. GC-MS quantitation of fragrance compounds suspected to cause skin reactions. I Agric Food Chem 2003; 51: 6398-403.

31. SHELLIE R, MARRIOTT P, CHAINTREAU A. Quantitation of suspected allergens in fragrances: evaluation of comprehensive two-dimensional GC for quality control. Flavour Fragr / 2004; 19: 91-8.

32. DEBONNEVILLE C, CHAINTREAU A. Quantitation of suspected allergens in fragrances: evaluation of comprehensive GC- conventional MS. J Chromatogr A 2004; 1027: 109-15.
33. VEIEN NK, HATTEL T, JUSTESEN O, NORHOLM A. Patch testing with perfume mixture. Acta Derm Venereol 1982; 62: 341-3.

34. JOHANSEN JD, MENNE T. The fragrance mix and its constituents: a 14-year material. Contact Dermatitis 1995; 32: 18-23.

35. ANDERSEN KE, RASTOGI SC, CARLSEN L. The allergen bank: a source of extra contact allergens for the dermatologist in practice. Acta Derm Venereol 1996; 76: 136-40.

36. SCHAFERT, BOHLER E, RUHDORFER S, et al. Epidemiology of contact allergy in adults. Allergy 2001; 56: 1192-6.

37. SCHEINMAN PL. Exposing Covert Fragrance Chemicals. Am / Contact Dermatitis 2001; 12: 225-8. 